\title{
TINY BUBBLES: AN OVERLOOKED OPTICAL CONSTITUENT
}

BY ERIC TERRILL AND MARLON LEWIS

While it can be imagined that one of the earliest descriptions of the ocean's surface viewed by man when he put forth to the ocean on rudimentary vessels might be the intensity of whitecapping, the science of understanding the influence of bubbles on marine light fields is an active area of research. Breaking waves at the ocean's surface inject bubbles and turbulence into the water column. During periods of rough weather, the scales of wave breaking tend to increase with increasing sea states, resulting in mixing of the surface waters and the turbulent transport of bubbles to depth. The bubbles injected by breaking will span several orders of magnitude in size from perhaps less than microns in diameter to $\mathrm{O}(1) \mathrm{cm}$. To complicate matters, the size distribution of bubble populations will evolve in time due to a complex interplay between the bubble rise speed, gas dissolution, surface tension, and turbulence, which are size-dependent, physical influences. In addition to breaking waves, bubble formation and stabilization result from biological processes such as photosynthesis in the surface layer, microbial decomposition in the sediments, the passage of low-pressure fronts that can bring gas out of solu- tion, and cavitation due to ships and other moving objects. The ubiquitous dissolved organic matter present in all oceans adheres onto bubbles almost immediately on formation, which significantly alters their physical dynamics, their optical characteristics, and potentially their gas dissolution rates.

Bubbles predominantly influence the optical properties of the upper ocean by scattering light. Their index of refraction, which is less than seawater, renders them very efficient at scattering; this is particularly true for the proportion of the total scattering in the backwards direction (see Boss et al., this issue). Despite the fundamental importance of particulate scattering for radiative transfer in the upper ocean, their central role in fixing the amplitude of light scattered out of the ocean, and their impacts on laser propagation, it is perhaps surprising that we cannot explain much more than 5 to 10 percent of the particulate backscattering in the ocean based on known constituents. Furthermore, we have been aware of this backscattering conundrum for a long time, almost as long as we have known its signifcance. One candidate to account for the "missing backscattering" is bubbles perhaps very small, stabilized bubbles, in the upper ocean.
The temporal and spatial variability of the bubble field has required the development of unique measurement approaches that include the use of underwater sound and optical imaging combined with the more traditional tools that optical oceanographers rely upon. For example, field efforts during the HyCODE program demonstrated with acoustic and optical techniques that the average optical scattering due to bubbles could range from $10^{-3} \mathrm{~m}^{-1}$ at a depth of $4 \mathrm{~m}$ to $10^{1} \mathrm{~m}^{-1}$ near the ocean surface during winds of $9 \mathrm{~m} / \mathrm{s}$ off the coast of New Jersey; significant increases were observed in the bubble component of the backscattering coefficient with the onset of high winds. Without accounting for bubbles, potentially large errors result in a wide variety of optical remote-sensing efforts including the remote-sensing retrieval of in-water constituents such as chlorophyll and laser imaging of the seafloor. 四

Eric Terrill (et@mpl.ucsd.edu) is Assistant Research Scientist, Marine Physical Laboratory, Scripps Institution of Oceanography. Marlon Lewis is Professor, Department of Oceanography, Dalhousie University, Halifax, Nova Scotia, Canada. 